all of which were related to the intense physical and mental load that his labour duties required. In June 2012, while driving to his job, he made a call to his wife where he tells her where he feared that he was being followed, the call was interrupted, he is helped by public security officers which found him on his car with alterations alertness, he is taken to the hospital, where is diagnosed with a hypertensive crisis, presenting haemorrhagic cerebrovascular disease, and entering into cardiac arrest causing death.

Conclusion According to the psychosocial risk factors, and the violence in the working environment, as multiple tasks are done, for example, prolonged shifts, chronic work-related stress, and the threats against his integrity and his family; the case is qualified as a death caused by Karoshi's syndrome.

\section{STRESS AND MENTAL HEALTH DUE TO WORKPLACE CONFLICTS IN KOREAN WORKERS}

${ }^{1} \mathrm{KH}$ HEO*, ${ }^{2} \mathrm{SY}$ LEE, ${ }^{2} \mathrm{JW}$ JEONG. ${ }^{1}$ Kosha Osh Training Institute. Ulsan, Korea; ${ }^{2}$ Korea Institute for Health and Social Affairs. Sejong Korea

\subsection{6/oemed-2018-ICOHabstracts.1712}

Introduction The purpose of this study is to analyse and analyse the current status and causes of conflicts in the personal and workplace, and analyse the factors affecting the mental health of workers such as suicide and addiction.

Method The study subjects were 753 workers in the workplace who agreed to the purpose of the survey and hoped to participate. After describing the purpose and method of the investigation to the safety and health manager who visited the Safety and Health Education Centre, each worker was asked for his/her consent to the desired workplace and conducted the Self-filling questionnaires. For family conflicts, a tool developed by the Korea Institute for Health and Social Affairs was used and, for the level of conflict related to job, the Korean Job Stress Measurement Tool (KOSS) was used. Social and emotional health was measured using 28 GHQ items, and depression was measured using 11 CES-D items. Work stress was analysed using SPSS WIN 20.0.

Results A survey of 753 workers showed that $80.9 \%$ of workers experienced at least one conflict and stress in the workplace during the three months preceding the survey. The average number of conflicts and stressors experienced by workers in the workplace was about 8.7 out of 26 , and the most common conflict and stress factors experienced by workers are those who need to perform various tasks at the same time, and $58.7 \%$ of workers have experienced it. The psychological burden of workers' family conflicts was found to have a greater psychological burden on women than men. Conflict and stress factors experienced by workers in the workplace were found to have a causal relationship that affected or affected the depressive symptoms and mental health of the workers. Job stress perceptions and experiences due to conflicts in the workplace were found to be lower in men than in women. Most workers are not systematically managing conflicts in the family and the workplace, and they are more likely to resolve themselves.

Conclusion According to a survey of 753 workers, in the previous three months, $80.9 \%$ of the workers experienced at least one conflict and stress in the workplace so that it is considered that the experience of stress due to conflict in the workplace of Korean workers is serious. The conflict and stress factors experienced by the Korean workers in the workplace seem to be related to the depressive symptoms and the mental health of the workers. Also, as mentioned above, the Korean people are not systematically managing conflicts in the family and the workplace, and they are characterised by strong tendency to resolve themselves. In order to cope with this situation, it is necessary to develop a variety of services and programs that meet the needs of consumers in the public sector and build up a regional service delivery system that can reach the public more aggressively. And it is necessary to develop and provide a mental health care program based on risk assessment that safety and health managers and small business employers can use in the field in relation to workplace stress management.

\section{JOB DEMAND CONTROL AND HYPERTENSION A CROSS- SECTIONAL STUDY IN COLOMBIAN TYPIST}

${ }^{1} \mathrm{~T}$ Hermida* ${ }^{2} \mathrm{~L}$ Briceño, ${ }^{1} \mathrm{R}$ Herrera, ${ }^{1} \mathrm{~K}$ Radon. ${ }^{1}$ Center for International Health @ Occupational Health, University Hospital Munich (LMU), Munich, Germany; ${ }^{2}$ Universidad del Rosario, Bogotá, Colombia

\subsection{6/oemed-2018-ICOHabstracts. 1713}

Introduction Hypertension has become a public health a worldwide challenge. It has been associated with psychosocial working conditions and with several chronic diseases. One of the job positions where poor psychosocial working condition might be present is a typist. We aimed to determine the prevalence of hypertension In Colombian typist population, associated with psychosocial factors at the work and identifying associated socio-demographic characteristics and employment conditions.

Methods Cross sectional interview-based questionnaire study and measurements (blood pressure, high, weigh) in 196 typist and 134 administrative workers from the same company in Colombia (response 100\%). Logistic regression models adjust to type of work, job demand control, Effort-Reward-Ratio, social support, age, gender and overweight.

Results The prevalence of hypertension in workers was $17.82 \%$. The age of workers was from 20 to 39 years (76.3\%). From the participants with high blood pressure, $31.2 \%$ had overweight, $21 \%$ reported high tension and $20 \%$ indicated active job ( $\mathrm{p}$ 0.36). The most important associations in the logistic regression, was overweight (OR 4.6; 95\% CI: 2.1 to 9.9), age between 30 and 40 years (OR 2.75; 95\% CI: 1.1 to 6.5 ), high social support (OR 2.45 ; 95\% CI: 1.1 to 5.1) and active job (OR 3.36; 95\% CI: 1.1 to 10.2).

Conclusions This study results indicate an increment of the prevalence of hypertension in Colombian young people, related to the epidemiological transition. It is an evidence of the need to shift the orientation of the country health programs to chronic diseases, such as the hypertension and overweight.

\section{IMPROVING MANAGEMENT SKILLS IN ADDRESSING EMPLOYEE STRESS}

${ }^{1}$ A Jones*, ${ }^{2}$ B Hayes. 'Specialist Registrar in Occupational Medicine, Beaumont Hospital, Dublin, Ireland; ${ }^{2}$ Consultant Occupational Physician, Beaumont Hospital, Dublin, Ireland

10.1136/oemed-2018-ICOHabstracts. 1714 